\title{
LA APLICACIÓN DE LA EXCEPCIÓN DE INCONVENCIONALIDAD COMO GARANTÍA DE PROTECCIÓN DE LOS DERECHOS POLÍTICOS EN COLOMBIA.
}

The application of unconventionality exception as protection guarantee of political rights in Colombia.

Jose Luis Palacios Ramirez ${ }^{1}$

Maria Alejandra Ramos Rezza ${ }^{2}$

\section{RESUMEN}

Los derechos políticos hacen parte de las garantías fundamentales que tienen las personas dentro de un Estado democrático y de derecho, contrarrestar esta libertad personal, constituye una violación al derecho internacional de los derechos humanos, por eso, preocupa que Colombia, viole los derechos políticos de sus administrados, cuando se le confiere poderes a la Procuraduría General de la Nación, para restringir derechos políticos, sin ser un órgano competente a la luz de la $\mathrm{CADH}$, que establece que los mismo pueden ser restringidos por juez penal competente, igualmente preocupa el hecho que la Corte Constitucional, mediante la Sentencia de 2006, ratifica dicha facultad, que hace aún más complejo el problema.

Mediante una metodología documental y analítica, se demostrara cómo si bien existe cosa juzgada al respecto, existe una ficha jurídica para proteger los derechos políticos de los colombianos, esto mediante un control de convencionalidad difuso por parte de los funcionarios públicos.

Palabras Claves: Derecho internacional de los Derechos Humanos, violación de derechos políticos, Estado social de derecho, control de convencionalidad difuso.

\section{ABSTRACT}

The political rights make part of the fundamental guarantees that people have within

\footnotetext{
${ }^{1}$ Egresado no graduado de la Facultad de Derecho y Ciencias Políticas de la Universidad Tecnológica del Chocó, "Diego Luis Córdoba" Integrante del Semillero de Investigación GIDEP, Semillero de Derechos Humanos, Derecho Procesal Constitucional. ORCID ID: https://orcid.org/0000-0002-8977-3215 E-mail: jlkpr95@gmail.com

${ }^{2}$ Egresada no graduada de la Facultad de Derecho y Ciencias Políticas de la Universidad Tecnológica del Chocó, "Diego Luis Córdoba”. ORCID ID: https://orcid.org/0000-0001-8027-1190 E-mail: marale.ramre96@gmail.com
} 
a democratic state of right, counteract this personal freedom constitutes an international right violation to the human rights, therefore it is worrying that Colombia violates the political rights of its administratives when it is given power to the prosecutor general to restrict political rights without being a competent entity in the light of $\mathrm{CADH}$, which establishes that the same can be restricted by a criminal court judge, at the same time, it is worrisome the fact that the constitutional court through the sentence of 2006 ratifies such power that makes more complex the problem.

By means of a documental and analytical methodology will be demonstrated the existence as if there existed such a judged thing. There exists a key legal adviser to protect the political rights of Colombian citizens, by means of a vague conventionality by the civil servants.

Key words: International right of human rights, political rights violation, welfare state, vague conventionality control.

\section{INTRODUCCION}

Los derechos políticos, según la Comisión Interamericana de Derechos Humanos, "son aquellos que reconocen y protegen el derecho, el deber de todos los ciudadanos de participar en la vida política de su país. Se trata de derechos que, por esencia, propician el fortalecimiento de la democracia y el pluralismo político" (CIDH, 2018, p.85)

Son diversos instrumentos internacionales que regulan los derechos políticos como una garantía de toda persona, sin embargo, es importante puntualizar en la Convención Americana de Derechos Humanos, la cual, para el caso de Colombia, es de obligatorio cumplimiento por haber ratificado dicho instrumento y aceptado la competencia de la Corte Interamericana de Derechos Humanos.

En el artículo 23, la Convención establece una serie de garantías frente al ejercicio de los derechos políticos, que, a su vez, tiene contenido de reglas con núcleo duro frente al Estado quien bajo dichos parámetros deberá abstenerse de limitarlos, y más bien, deberá interpretarlos como instrumentos vivos, de conformidad con la evolución de su ciudadanía y sus condiciones de vida actual.

Ahora bien, hoy preocupa como la constitución del Estado colombiano, frente al ejercicio y restricción de los derechos políticos no se encuentra conforme a la convención y las obligaciones de respeto y garantía que de ella deviene. En consecuencia, hoy se cuestiona que unos derechos tan importantes como los políticos, materializados en elegir y ser elegido, sean restringidos por la Procuraduría General de la Nación, facultad que le da la misma Constitución en su art. 277 numeral 6 que fue declarado exequible por la Corte Constitucional en sentencia C-028 de 2006, sin hacer un escáner propio a las limitaciones que impone la CADH en el ejercicio de estas garantías, generando inseguridad jurídica 
frente a las protecciones plenas que genera un Estado democrático y social derecho.

Por lo anterior, bajo una metodología documental, de cohorte descriptiva, en este escrito se pretende cuestionar la forma de limitar el derecho a elegir y ser elegido en Colombia, por órgano un incompetente a la luz de la CADH, más cuando el Procurador General de la Nación, es elegido de una terna que nombra el Presidente de la Republica, lo que hace que este órgano no sea totalmente imparcial, y que en sus decisiones frente a la restricción de estas garantías haya una especie de tinte político anexo a ello.

En tal sentido, en este escrito se pretende visionar a través de instrumentos jurídicos como el control de convencionalidad difuso, se podrían proteger los derechos políticos de los colombianos que aspiren a cargos de elección popular, tal como ya lo mencionaba el Consejo de Estado en el caso de Gustavo Petro Urrego y así evitar posibles condenas a Colombia por parte del Tribunal Internacional.

\section{Antecedentes del Estado de Derecho y transición al Estado Constitucional de Derecho.}

No debemos olvidar que entre otros factores de la época, gracias a "las ideas de Montesquieu (Principio de Separación de Poderes Publico, Principio de Legalidad, etc.) se crea el Estado de Derecho en donde ya no se debe hablar de un gobierno de hombres, sino de un gobierno de leyes" (Locke, 2006, pp. 131-142), es cuando inicia con el sometimiento de las actuaciones del Estado como la formulación de políticas públicas, control a los órganos particulares y públicos, un importante elemento de este paradigma, a saber, el principio de legalidad que obliga al Estado a no ser arbitrario y a sujetarse al contrato social, suscrito por él y sus asociados.

Zagrebelsky, relata cómo nació el Estado de Derecho en el siglo XVIII, y señala que:

Es el producto de las ideas liberales y la revolución francesa en contra del Machtstaat (Estado bajo el régimen de fuerza) y el Polizeistaat (Estado bajo el régimen de Policía) en donde el poder estaba concentrado en mano de un solo hombre. (Zagrebelsky, 2009, pp 21-45).

El siglo XVIII coloca situaciones desiguales donde los poderes del poder público se subordinan al poder ejecutivo, no existe un equilibrio de poderes razón por la que urge la transición de un Estado de derecho a un Estado social y constitucional de derecho que dotara de garantías y derechos fundamentales a sus asociados, además que se le entregara un valor preponderante al termino dignidad humana, vale recordar que dentro del Estado Social de Derecho Colombiano se entiende la dignidad humana según la Corte Constitucional:

La dignidad humana equivale: (i) al merecimiento de un trato especial que tiene toda persona por el hecho de ser tal; y (ii) a la facultad que tiene toda persona de exigir de los demás un trato acorde con su condición humana. Por tanto, la dignidad humana se erige como un derecho 
fundamental, de eficacia directa, cuyo reconocimiento general compromete el fundamento político del Estado. (Corte Constitucional, T-291 de 2016, M.P. Alberto Rojas Ríos, p. 1).

Dicho lo anterior debemos decir que según el maestro "Guastini 2001, las principales condiciones para que hablemos de un Estado Constitucional de Derecho son:

a) La existencia de una constitución rígida, que incorpora los derechos fundamentales.

b) La garantía jurisdiccional de la constitución.

c) La fuerza vinculante de la constitución (que no es un conjunto de normas “programáticas" sino "preceptivas")

d) La "sobreinterpretación" de la constitución (se le interpreta extensivamente y de ella se deducen principios implícitos)

e) La aplicación directa de las normas constitucionales, también para regular las relaciones entre particulares.

f) La interpretación adecuadora de las leyes.

g) La influencia de la constitución sobre el debate político.” (López José, 2018, p 56).

Es de aquí según la opinión de Guastini que parte un Estado social y constitucional de derecho, lo que en otras palabras nos trasmite todos los temas que deben tocar las constituciones modernas, ya lo decía éste, la creencia en el respeto de la dignidad humana y la democracia que para los intereses de este trabajo investigativo, son pilares que aunque no se mencionan están inmersos dentro de cualquier Estado que intente garantizar el libre y pleno ejercicio de los derechos fundamentales a sus habitantes.

Con relación a lo anterior la Corte Constitucional colombiana señaló en la sentencia T 406 de 1992, los valores supremos que componen el Estado de Derecho Colombiano, en ese orden indicó que:

De este tipo son los valores de convivencia, trabajo, justicia, igualdad, conocimiento, libertad y paz plasmados en el preámbulo de la Constitución. También son valores los consagrados en el inciso primero del artículo 2 de la Constitución en referencia a los fines del Estado: el servicio a la comunidad, la prosperidad general, la efectividad de los principios, derechos y deberes, la participación, etc. Todos ellos establecen fines a los cuales se quiere llegar. La relación entre dichos fines y los medios adecuados para conseguirlos, depende, por lo general, de una elección política que le corresponde preferencialmente al legislador. No obstante, el carácter programático de los valores constitucionales, su enunciación no debe ser entendida como un agregado simbólico, o como la manifestación de un deseo o de un querer sin incidencia normativa, sino como un conjunto de propósitos a través de los cuales se deben mirar las relaciones entre los gobernantes y los gobernados, para que, dentro de las limitaciones propias de una sociedad en proceso de consolidación, irradien todo el tramado institucional. (Corte Constitucional, T 406 de 1992. M.P Ciro Angarita Barón, p. 10)

De las peculiaridades que conforman a un Estado Constitucional de derecho citadas anteriormente 
por el maestro Guastini, encontramos que la jurisprudencia colombiana define al Estado Social de derecho como:

La acepción Estado de derecho se refiere a que la actividad del Estado está regida por las normas jurídicas, es decir que se ciñe al derecho. La norma jurídica fundamental es la Constitución, lo cual implica que toda la actividad del Estado debe realizarse dentro del marco de la última. En esta situación se habla entonces de Estado constitucional de derecho (Corte Constitucional, SU 747 de 1998, M.P, Eduardo Cifuentes Muñoz, p. 1).

Josep Aguilo afirma que la teoría de la constitución, se convierte en un fragmento central de la teoría del derecho, y sobre ella se proyectan muchas de las disyuntivas del derecho (Aguilo, 2004, pp 23-24), y es que el rol que juega la constitución en un Estado, es fundamental porque no sólo nos señala las funciones que cumple cada órgano, sino que además en ella reposan los derechos fundamentales, la distribución del poder público.

Ahora bien, según la opinión del maestro José Reynaldo López, en su trabajo titulado "Del Estado de Derecho al Estado Constitucional de Derecho. La Aparición del Derecho Procesal Constitucional":

Desde hace muchos años, la mayoría de Estados Constitucionales viven lo que se denomina el fenómeno de la constitucionalización, dentro del cual uno de los aspectos más relevantes es la subordinación de la ley y cualquier otro tipo de acto estatal e inclusive particular, a los principios, valores y derechos que presenta la Constitución, como un plexo armónico, orgánico y sobre todo directamente efectivo. (López. 2018, p. 53-54).

Bien lo plantea Salgado (2017):

La constitución moderna, vista desde una perspectiva de análisis de naturaleza universal, configura en sí misma los lineamientos dogmáticos en los que descansan una multiplicidad de valores, principios y derechos, los cuales han de servir como criterios de orientación necesarios para la conformación de cualquier Estado democrático moderno. Naturalmente, esto no se refiere a un concepto de dogma como un sistema de carácter cerrado e inmutable, sino a una sistematización integrada de carácter abierta y progresista de elementos fundamentales y esenciales que son el soporte y razón misma de ser del Estado. La Constitución colombiana de 1.991, inspirada en un Estado social y democrático de derecho, no es la excepción; en efecto, en su artículo $4^{\circ}$ deja plasmado un sistema de alternativas filosóficas y de conceptos de derecho. (p. 23)

Hoy el debate acerca de la supremacía constitucional con relación a las leyes o cualquier otro acto estatal, está saneado en el sentido de que la constitución cuenta con la característica de supra-legalidad, es por tal razón que en Estados como el colombiano, se realiza un control de constitucionalidad a las leyes estatutarias antes de su nacimiento jurídico, tal y como lo señala el artículo 241 numeral 8 "Decidir definitivamente sobre la constitucionalidad de los proyectos de ley que hayan sido objetados por el Gobierno como inconstitucionales, y de los proyectos de leyes estatutarias, 
tanto por su contenido material como por vicios de procedimiento en su formación" (Const., 1991, art. 241 numeral 8), se busca puntualmente que los artículos que presenta la ley que implique derechos fundamentales sea sometida a control de constitucionalidad para que no se contraríe lo estipulado por la máxima norma del ordenamiento jurídico, que para este caso es la Constitución Política Colombiana.

Para cerrar este punto, es prudente señalar el propósito de un Estado social de derecho en palabras el maestro Alexy (2007): "los derechos ya no son concebidos como meras normas preceptivas, sino como principios que exigen un máximo desarrollo de optimización por parte de todos los órganos estatales y no estatales" (López José, 2018, p 58), esa exigencia de optimizar los derechos, son obligaciones que tienen los Estados, de lograr un desarrollo progresivo de sus pueblos en donde estos alcances niveles de vida dignos, que le permitan realizar sus proyectos de vida $(\mathrm{CADH}$, 1969, art. 26.1).

\section{Obligaciones Internacionales, garantía de los Derechos Humanos.}

El artículo XX de la Declaración Americana de Derechos y Deberes del Hombre señala que, toda persona, legalmente capacitada, tiene el derecho de tomar parte en el gobierno de su país, directamente o por medio de sus representantes, y de participar en las elecciones populares, que serán de voto secreto, genuino, periódico y libre (Decl. Americana, art. 20,1948,).

Quedando claro el derecho que tiene cualquier persona de ocupar cargos públicos de manera periódica y libre, de esta se desprende el compromiso de los Estados de asegurar que lo dispuesto por dicha declaración sea una realidad al interior de los mismos.

Así, a nivel internacional encontramos al Sistema Interamericano de Derechos Humanos, en adelante SIDH, cuya tarea es la de regular el ejercicio de los derechos políticos, el disfrute de estos derechos como también, sus límites; dichos limites han sido definidos por la Convención Americana de derechos humanos en adelante CADH y la Corte Interamericana de derechos humanos en adelante Corte IDH, dentro del SIDH, los derechos políticos son entendidos como "aquellos que reconocen y protegen el derecho y el deber de todos los ciudadanos de participar en la vida política de su país” (CIDH, Informe sobre la situación de derechos humanos en Venezuela, 2009. Párr. 18).

En ese orden de ideas la $\mathrm{CADH}$ en su artículo 23 inciso 1 señala que:

Todos los ciudadanos deben gozar de los siguientes derechos y oportunidades:

a) de participar en la dirección de los asuntos públicos, directamente o por medio de 
representantes libremente elegido.

b) de votar y ser elegidos en elecciones periódicas auténticas, realizadas por sufragio universal e igual y por voto secreto que garantice la libre expresión de la voluntad de los electores, $\mathrm{y}$

c) de tener acceso, en condiciones generales de igualdad, a las funciones públicas de su país. (CADH, 1969, art. 23.1).

Ese mismo artículo en su inciso segundo menciona las restricciones a este derecho, expresando taxativamente cuales son las razones que podrían adoptar los Estados sujetos a su jurisdicción para limitarlo, puntualmente: "La ley puede reglamentar el ejercicio de los derechos y oportunidades a que se refiere el inciso anterior, exclusivamente por razones de edad, nacionalidad, residencia, idioma, instrucción, capacidad civil o mental, o condena, por juez competente, en proceso penal". (CADH, 1969, art. 23.2)

El SIDH desde sus primeros fallos ha señalado que los Estados, están obligados a cumplir lo estipulado por la $\mathrm{CADH}$, haciendo remisión expresa a la obligación de respeto y garantía contenida en el artículo 1.1 y 2 convencional, entendiendo la primera "como la obligación positiva de asegurar la efectividad de los derechos humanos protegidos, que existe en cabeza de los Estados" (Medina, 2009, p. 18), mientras que la obligación de garantía se refiere:

Al libre y pleno ejercicio de los derechos reconocidos en la $\mathrm{CADH}$, a toda persona sujeta a su jurisdicción, como también organizar todo su aparato gubernamental y en especial todas las estructuras a través de las cuales se manifiesta el poder público, de manera tal que sean capaces de asegurar jurídicamente el libre y pleno ejercicio de los derechos humanos. (Corte IDH, 1988, p. 34-35).

De lo anterior podemos colegir que los Estados en aplicación del principio pacta sun servanda, que no es otra cosa que respetar los tratados internacionales de buena fe según (Kunz, s.f, p. 8), en cumplimiento del principio anteriormente mencionado de respetar y acatar lo dispuesto por la $\mathrm{CADH}$, con relación a lo que dispone el artículo 23, en sus dos incisos, sin embargo, casos como Yatama Vs Nicaragua (Corte IDH, 2005), Tribunal Constitucional Vs Perú(Corte IDH, 2001), Castañeda Gutman Vs México(Corte IDH, 2009), López Mendoza Vs Venezuela(Corte IDH, 2011), Tribunal Constitucional Vs Ecuador (Corte IDH, 2013), López Lone Vs Honduras (Corte IDH, 2015), nos permite inferir que las obligaciones internacionales no han logrado permear los sistemas jurídicos de los Estados, como se esperaba, hay que decir como primero que Colombia ratificó la CADH en 1972 (Ley 16 de 1972), por lo cual el Estado está obligado a cumplir de buena fe lo estipulado por dicho instrumento, es tanto así que lo dispuesto por la Corte IDH, ha servido para que países como México incorporen dentro de sus ordenamientos jurídicos internos las obligaciones anteriormente 
mencionadas de la siguiente manera:

En los Estados Unidos Mexicanos todas las personas gozarán de los derechos humanos reconocidos en esta Constitución y en los tratados internacionales de los que el Estado Mexicano sea parte, así como de las garantías para su protección, cuyo ejercicio no podrá restringirse ni suspenderse, salvo en los casos y bajo las condiciones que esta Constitución establece. (Const., 2011, art. 1)

En consonancia con lo anterior, hay que tener presente que la Constitución política Colombiana, faculta a la Procuraduría General de la Nación a restringir derechos políticos (Const., 1991, art. 277 numeral 6), un detalle de mucha importancia para esta investigación es que el artículo 93 de la Constitución Colombiana, crea la figura llamada bloque de constitucionalidad, donde:

La Corte Constitucional ha establecido que la revisión de constitucionalidad de los asuntos sometidos a su competencia, debe realizarse no sólo frente al texto formal de la Carta, sino también a partir de su comparación con otras disposiciones, las cuales de acuerdo con la Constitución tienen jerarquía constitucional (Corte Constitucional, C 774 de 2001. M. P. Rodrigo Escobar Gil. p 9).

Esto quiere decir tal y como lo señala Quiniche (Quinche, 2009, p. 169), que las autoridades están autorizadas a utilizar los tratados internacionales como fuente de interpretación e interpretarlos como parte de la legislación nacional, siempre y cuando el Estado Colombiano los haya ratificado.

\section{Interpretación de los Derechos Políticos dentro del Sistema Regional de los Derechos Huma- nos, Corte Interamericana de Derechos Humanos.}

"En el continente americano, la democracia tiene un papel fundamental en la formación y el desarrollo de la Organización de los Estados Americanos (OEA) y en la creación y evolución del Sistema Interamericano de Protección de los Derechos Humanos," (Dalla, 2011, p. 22) quedando claro que los derechos políticos representan el cimiento de las sociedades democráticas.

Los derechos políticos son derechos de titularidad individual de los ciudadanos que frecuentemente se ejercen de manera conjunta o agrupada como son la libertad de expresión, el derecho de reunión y manifestación, y el derecho de asociación en partidos, por lo que están relacionados con los derechos de ejercicio colectivo, que pueden realizarse con fines políticos. (Dalla, 2011, pp. 28-29).

Frente a la clara contradicción existente entre la CADH y la Constitución Colombiana, con relación a la restricción de los derechos políticos, el Estado colombiano se basa en el principio de libre configuración legislativa en materia disciplinaria que tiene como finalidad especifica "La prevención y buena marcha de la gestión pública, así como la garantía del cumplimiento de los fines y funciones del Estado en relación con las conductas de los servidores públicos que los afecten o pongan en peligro" (Corte Constitucional, Sala Plena, SPD3937-D3944, 2002), este principio sirvió como base para 
que el legislador expidiera en el año 2002 la ley 734, que sería el Código Único Disciplinario, que ampliaría las facultades de la procuraduría general de la Nación para la restricción de los derechos políticos, precisamente podemos vislumbrar el problema recurriendo a dos artículos especiales de la ley, primeramente el artículo 44 en su numeral 1 establece "la destitución e inhabilidad general, para las faltas gravísimas dolosas o realizadas con culpa gravísima" (Código Único Disciplinario, 2002), no obstante, el artículo 45 de esta misma ley que en su numeral 1 literal a, especifica hacia quienes va dirigida la sanción antes citada, cuando establece que la "destitución e inhabilidad general implica, la terminación de la relación del servidor público con la administración, sin que importe que sea de libre nombramiento y remoción, de carrera o elección popular," (Código Único Disciplinario, 2002).

Dicha dicotomía era merecedora de un control de constitucionalidad, debido a que la CADH, establece un trato totalmente distinto a los servidores públicos, elegidos por elección popular, por eso la Corte Constitucional colombiana, ejerciendo las funciones de salvaguarda de la Constitución, debido a la contradicciones entre las normas constitucionales, realizó en el año 2006 un control de constitucionalidad, donde decidió declarar exequible las facultades de la procuraduría general de la Nación para restringir los derechos políticos, basado en que:

Así las cosas, es menester indicar que el derecho a acceder al ejercicio de las funciones públicas, como ningún otro derecho fundamental, puede ser considerado como absoluto. Por el contrario, el legislador puede limitarlo, puesto que sobre el mismo se hacen efectivas ciertas restricciones, que se justifican esencialmente en la consecución de la prevalencia del interés general y de los principios que deben orientar el cumplimiento de la función pública, se reitera, todo ello en aras a la consecución de los fines estatales y de la transparencia y probidad de quienes ejercen la función pública, por ello no podría decirse que con las normas acusadas se afectan dicho derecho, en la medida en que dicha restricción se encuentra justificada. (Corte Constitucional, 2006)

Esta situación permitió que la Procuraduría General de la Nación, siguiera ejerciendo funciones que a la luz de la CADH y las sentencias desarrolladas por la Corte IDH, son totalmente contrarias al SIDH. Hay que recordar que la corte IDH señaló que:

La previsión y aplicación de requisitos para ejercitar los derechos políticos no constituyen, per se, una restricción indebida a los derechos políticos. Esos derechos no son absolutos y pueden estar sujetos a limitaciones. Su reglamentación debe observar los principios de legalidad, necesidad y proporcionalidad en una sociedad democrática. La observancia del principio de legalidad exige que el Estado defina de manera precisa, mediante una ley, los requisitos para que los ciudadanos puedan participar en la contienda electoral, y que estipule claramente el procedimiento electoral que antecede a las elecciones. De acuerdo al artículo 23.2 de la Convención se puede reglamentar el ejercicio de los derechos y oportunidades a las que se refiere el inciso 1 de dicho artículo, exclusivamente por las razones establecidas en ese inciso. La restricción debe encontrase prevista en una ley, no ser discriminatoria, basarse en criterios razonables, atender a un propósito útil y oportuno que la torne necesaria para satisfacer un 
interés público imperativo, y ser proporcional a ese objetivo. Cuando hay varias opciones para alcanzar ese fin, debe escogerse la que restrinja menos el derecho protegido y guarde mayor proporcionalidad con el propósito que se persigue. (Corte IDH. 2005, p 91)

De acuerdo a lo anterior la corte IDH, indicó puntualmente que las normas que restrinjan los derechos políticos deben, basarse en el inciso 2 del artículo 23 y que luego deben cumplir criterios de utilidad, oportunidad, que satisfaga un interés público, y que sea proporcional, como se puede observar cuando la Corte Constitucional Colombiana decide la mantener las funciones entregadas a la Procuraduría en materia de derechos políticos, ya no está pasando por alto únicamente lo estipulado por el tratado internacional, sino además lo decidido por el máximo intérprete de dicho instrumento.

Además la corte IDH, a través de la sentencia del caso "Almonacid Arellano contra el Estado Chileno" concluyó que:

La descrita obligación legislativa del artículo 2 de la Convención tiene también la finalidad de facilitar la función del Poder Judicial de tal forma que el aplicador de la ley tenga una opción clara de cómo resolver un caso particular. Sin embargo, cuando el Legislativo falla en su tarea de suprimir y/o no adoptar leyes contrarias a la Convención Americana, el Judicial permanece vinculado al deber de garantía establecido en el artículo 1.1 de la misma y, consecuentemente, debe abstenerse de aplicar cualquier normativa contraria a ella. El cumplimiento por parte de agentes o funcionarios del Estado de una ley violatoria de la Convención produce responsabilidad internacional del Estado, y es un principio básico del derecho de la responsabilidad internacional del Estado, recogido en el Derecho Internacional de los Derechos Humanos, en el sentido de que todo Estado es internacionalmente responsable por actos $\mathrm{u}$ omisiones de cualesquiera de sus poderes u órganos en violación de los derechos internacionalmente consagrados, según el artículo 1.1 de la Convención Americana. (Corte IDH. 2006a, pp 52- 53).

También este tribunal, señaló:

La corte es consciente de que los jueces y tribunales internos están sujetos al imperio de la ley y, por ello, están obligados a aplicar las disposiciones vigentes en el ordenamiento jurídico, pero cuando un Estado ha ratificado un tratado internacional como la Convención Americana, sus jueces, como parte del aparato del Estado, también están sometidos a ella, lo que les obliga a velar porque los efectos de las disposiciones de la Convención no se vean mermadas por la aplicación de leyes contrarias a su objeto y fin, y que desde un inicio carecen de efectos jurídicos. En otras palabras, el Poder Judicial debe ejercer una especie de "control de convencionalidad" entre las normas jurídicas internas que aplican en los casos concretos y la Convención Americana sobre Derechos Humanos. En esta tarea, el Poder Judicial debe tener en cuenta no solamente el tratado, sino también la interpretación que del mismo ha hecho la Corte Interamericana, intérprete última de la Convención Americana. (Corte IDH. 2006b, p 53)

La corte IDH, entiende que la conformación de una ley puede contraer errores, y que estos pueden afectar los derechos contenidos en la $\mathrm{CADH}$, por eso exhorta al poder judicial, para enmendar 
esos errores, y por si no fuese poco, además le dice a todos los funcionarios públicos, que cuando una norma expedida por el legislador vaya en contravía de lo estipulado por el pacto de San José, inapliquen esa norma y adopten preferentemente lo establecido por la CADH.

En el año 2005, Colombia hizo caso omiso a lo señalado por la corte IDH, tanto así que las funciones de la Procuraduría General de la Nación, hasta la fecha siguen intactas.

Los derechos políticos y la protección en el SIDH son cada vez más relevantes, tanto así que la corte IDH, indicó en la sentencia del caso “Castañeda Gutman contra el Estado Mexicano" que:

La facultad de los Estados de regular o restringir los derechos no es discrecional, sino que está limitada por el derecho internacional que exige el cumplimiento de determinadas exigencias que de no ser respetadas transforma la restricción en ilegítima y contraria a la Convención Americana. (Corte IDH. 2009, p 50)

A pesar del principio de libre configuración normativa con el que cuentan los Estados, existen unos parámetros señalados por la misma $\mathrm{CADH}$, que deben respetarse debido a que los tratados internacionales, deben cumplirse de buena fe, sino se respeta lo señalado la restricción, en este caso se transforma en ilegítima y contraría a la $\mathrm{CADH}$, por lo que no tendría ninguna validez, así sea avalada por la Corte Constitucional.

Para esclarecer este asunto, vale la pena citar lo que la corte IDH, en la sentencia de Leopoldo López contra Venezuela, determinó:

El artículo 23.2 de la convención determina cuáles son las causales que permiten restringir los derechos reconocidos en el artículo 23.1, así como, en su caso, los requisitos que deben cumplirse para que proceda tal restricción. En el presente caso, que se refiere a una restricción impuesta por vía de sanción, debería tratarse de una "condena, por juez competente, en proceso penal. (Corte IDH. 2011a, p 45)

A través de esta sentencia la corte IDH, notificó a los Estados sujetos a su jurisdicción que los derechos políticos, no debían ser restringidos por vía de sanción, como sucede aún en el territorio colombiano y que sólo estaban investidos de competencia para limitar estos derechos un juez competente a través de un proceso penal.

En ese mismo fallo la corte deja entrever el por qué del deseo del SIDH, de que las restricciones enumeradas en el artículo 23.2 sean impuesta por una autoridad judicial al señalar lo siguiente:

Ninguno de esos requisitos se ha cumplido, pues el órgano que impuso dichas sanciones no era un "juez competente", no hubo "condena" y las sanciones no se aplicaron como resultado de un 
"proceso penal", en el que tendrían que haberse respetado las garantías judiciales consagradas en el artículo 8 de la Convención Americana.(Corte IDH. 2011b, p 45)

Por eso es importante reiterar que "el ejercicio efectivo de los derechos políticos constituye un fin en sí mismo y, a la vez, un medio fundamental que las sociedades democráticas tienen para garantizar los demás derechos humanos previstos en la Convención.” (Corte IDH. 2009, p 42)

El Estado colombiano, después de declarar la constitucionalidad de la ley 734 de 2002, volvió a estar en el ojo del huracán, debido a que el máximo órgano del ministerio público, la Procuraduría General de la Nación decidió restringir por vía de sanción, los derechos políticos del entonces Alcalde de Bogotá, Gustavo Francisco Petro Urrego, dicha decisión le dio la vuelta al país, pero lo que en verdad inquietaba a la sociedad era preguntarse ¿es competente la procuraduría general de la Nación, para arrebatarle los derechos políticos al señor, Gustavo Petro y además a las personas que votaron por él o se sienten representadas por él?

El 15 de noviembre de 2017 el Consejo de Estado emitió la sentencia en la que el señor Gustavo Petro figuraba como parte argumentando que:

Ahora bien, un control de convencionalidad del artículo 44.1 de la Ley 734 del 2002, fundamento sancionatorio en el presente caso, permite advertir una incompatibilidad entre tal disposición y el artículo 23.2 convencional y concluir, de manera diáfana, que la Procuraduría General de la Nación carecía de competencia para imponer una sanción que restringiera, casi que a perpetuidad, los derechos políticos de una persona para ser elegida en cargos de elección popular, como también para separarlo del cargo de Alcalde Mayor de Bogotá para el que fue elegido mediante sufragio universal. (Consejo de Estado, 2017a, p. 31)

Este fue el primer paso que dio el Estado Colombiano, para anular las funciones de la Procuraduría General de la Nación, que si recordamos bien, las normas demandadas fueron declaradas exequibles, por la Corte Constitucional en la sentencia C 028 de 2006, por lo que goza de Cosa Juzgada Constitucional.

El Consejo de Estado además manifiesta que:

En este sentido, la interpretación que la Sala Plena de lo Contencioso Administrativo del Consejo de Estado hace del artículo 277 de la Constitución Política, en su numeral 6 que dispone como una de las funciones del Procurador General de la Nación la de "ejercer vigilancia superior de la conducta oficial de quienes desempeñen funciones públicas, inclusive las de elección popular; ejercer preferentemente el poder disciplinario; adelantar las investigaciones correspondientes e imponer las respectivas sanciones conforme a la ley", debe corresponder a una hermenéutica que mejor armonice con la protección de los derechos humanos, en aplicación del principio de favorabilidad o pro hominem, en este caso, de los derechos políticos de los servidores de elección popular. Derechos que, conforme con el artículo 23.2 de la $\mathrm{CADH}$, no pueden ser restringidos 
sino por un funcionario con jurisdicción, mediante una sentencia judicial dictada dentro de un proceso de la misma naturaleza. (Consejo de Estado, 2017b, pp. 34, 35)

En este control difuso de convencionalidad, que realizó el Consejo de Estado, aplicando preferentemente la $\mathrm{CADH}$, queda más que claro que las funciones de la procuraduría, son totalmente contrarias a lo estipulado en el Pacto de San José, y que lamentablemente la Corte Constitucional se equivocó al mantener las funciones de la Procuraduría intactas en el año 2006.

\section{Cultura de aplicación de la Excepción de Inconvencionalidad, como herramienta para la protección de los derechos políticos.}

El artículo 93 de la constitución señala que "los tratados y convenios internacionales ratificados por el congreso, que reconocen los derechos humanos y que prohíben su limitación, en los estados de excepción, prevalecen en el orden interno" (Const., 1991, art. 93) es aquí donde se genera la obligación del Estado colombiano de respetar los derechos humanos aun en los estados de excepción, pero llegando más allá, se instala la figura jurídica del Bloque de Constitucionalidad en Colombia a través del artículo 93 de la carta magna, la cual es definida por la Corte Constitucional como:

Aquella unidad jurídica compuesta por normas y principios que, sin aparecer formalmente en el articulado del texto constitucional, son utilizados como parámetros del control constitucionalidad de las leyes, por cuanto han sido normativamente integrados a la Constitución. Son pues verdaderos principios y reglas de valor constitucional, esto es, son normas situadas en el nivel constitucional, a pesar de que puedan a veces contener mecanismo de reformas diversas al de las normas del articulado constitucional strictu sensu. (Corte Constitucional, C 067 de 2003. M.P. Marco Gerardo Monroy Cabra, p. 1)

La Corte Constitucional deja claro que a pesar de que las normas del tratado internacional no aparecen formalmente en el texto constitucional, cuando se hace el control de constitucionalidad a las leyes, o la aplicación de criterios interpretativos, están deben de ser consideradas como normas que integran el ordenamiento jurídico Colombiano.

Es en este orden de ideas podemos entender porque el Estado colombiano está en la obligación de cumplir y aplicar preferentemente los postulados que reposan en los convenios internacionales relacionados con la garantía de los derechos políticos, ya que existe la la figura de bloque de constitucionalidad.

\section{CONCLUSIÓN}

El SIDH está dotado de herramientas para asegurar la protección de los derechos reconocidos en la $\mathrm{CADH}$ y los instrumentos internacionales que componen al sistema, en el desarrollo de este trabajo hemos notado que a pesar de que un Estado como el colombiano ha ratificado la CADH, 
y además ha aceptado la competencia de la corte IDH, se siguen presentando violaciones de derechos humanos que afectan a la personas como también a al ordenamiento porque producen inseguridad jurídica.

Así, la Procuraduría General de la Nación, aún ostenta sus facultades para restringir derechos políticos, mas allá de haber demostrado a lo largo de este trabajo investigativo, que no es un ente autorizado por el SIDH para dicha función, como lo puntualizó el Consejo de Estado en la sentencia del 15 de noviembre de 2017, en donde decidió restaurar los derechos políticos de Gustavo Petro Urrego, aplicando una excepción de inconvencionalidad, como lo hemos planteado, además no podemos olvidar que los derechos políticos son derechos fundamentales, y por lo tanto, es la Corte Constitucional la que está llamada a pronunciarse de fondo respecto a esta situación, porque cuando se restringen los derechos políticos de una persona que representa los intereses un conglomerado de personas, no solamente se está vulnerando ese derecho político de manera activa, sino también de manera pasiva, porque quienes se ven representados, por eso es importante que la Corte Constitucional, tome responsabilidad respecto al tema, y decida y limite las funciones de un órgano de control como lo es la Procuraduría, pues con esta serie de eventos las personas integrantes de este Estado de Derecho están a la intemperie con relación a este derecho Fundamental.

\section{REFERENCIAS BIBLIOGRAFICAS}

Josep Aguilo, La Constitución del Estado Constitucional, Palestra Editores, 23-24. (2004).

Robert Alexy, Teoría de los Derechos Fundamentales, Centro de estudios Políticos y Constitucionales. (2007).

CIDH. Informe sobre la situación de derechos humanos en Venezuela, OEA/OEA/Ser.L/V/II. Doc. 54. (30 de diciembre de 2009).

CIDH. Situación de los derechos humanos en Venezuela, OEA/Ser.L/V/II. Doc 209. (31 de diciembre de 2017)

Ley 16 de 1972. Por medio de la cual se aprueba la Convención Americana sobre Derechos Humanos "Pacto de San José de Costa Rica", firmado en San José, Costa Rica, el 22 de noviembre 1969. 30 de diciembre de 1972. D.O. No. 33780.

Constitución Política de Colombia [Const]. Arts.4,93,119,24. 7 de julio de 1991. (Colombia).

Constitución Política de los Estados Unidos Mexicanos [Const]. Art. 1.(5 de febrero de 1857). Art. 
1. 5 de febrero de 1917. (México).

Convención Americana de Derechos Humanos. Arts. 1, 2, 8, 23, 26. 22 de noviembre de 1969.

Alberto Ricardo Dalla Via, Derechos Políticos, normativa electoral y equidad en los procesos electorales, Cuaderno de capel 57, 28. (2011).

Alberto Ricardo Dalla Via, Los Derechos Políticos en el Sistema Interamericano de Derechos Humanos, Revista Justicia Electoral, agosto de 2011, At. 16.

Declaración Americana de Derechos y Deberes del Hombre. Aprobada en la IX conferencia internacional Americana, Bogotá, Colombia. 1948.

Ricardo Guastini, La Constitucionalizacion del ordenamiento: El caso italiano, Estudios de teoría constitucional. (2001).

Josef Kunz, El sentido y el alcance de la norma "Pacta Sun Servanda". 8. (1946). https:// revistas-colaboracion.juridicas.unam.mx/index.php/escuela-nal-jurisprudencia/article/ view/20628/18534

Jhon Locke, Segundo Tratado sobre el Gobierno Civil, Ed.Tecnos, 131-142. (2006).

José López,Garantía Jurisdiccional de la Constitución: Del Estado de Derecho al Estado Constitucional de Derecho. La Aparición del Derecho Procesal Constitucional, VC Editores Ltda, 53-54. (2018).

Felipe Medina Ardila, La responsabilidad internacional del Estado por actos de Particulares análisis jurisprudencial interamericano, Revista Debate interamericano, 2009, At.89.

Manuel Fernando Quinche Ramírez, El Control de Convencionalidad y el Sistema Colombiano, Revista Iberoamericana de Derecho Procesal Constitucional, julio de 2009, At. 163.

Salgado González, A. (2017) Constitución y Derechos Humanos. Revista Jurídica Mario Alario D’Filippo, 9, (18): 21-30. Recuperado de DOI: https://doi.org/10.32997/2256-2796-vol.9num.18-2017-2051

Gustavo Zagrebelsky, El Derecho Dúctil: Ley, derechos, justicia, Editorial Trotta, 21-45. (2009). 


\section{Jurisprudencia}

Consejo de Estado. Sala Plena de lo Contencioso Administrativo. No 1131-2014, C. P. Cesar Palomino Cortés.

Corte Constitucional de Colombia; M.P. Ciro Angarita Barón; 1992; Sentencia T-406 de 1992.

Corte Constitucional de Colombia; M.P. Alberto Rojas Ríos; 2016; Sentencia T-291 de 2016.

Corte Constitucional de Colombia; M.P. Marco Gerardo Monroy Cabra; 2013; Sentencia C-067 de 2003.

Corte Constitucional de Colombia. M. P. Rodrigo Escobar Gil; 2001; Sentencia C-774 de 2001.

Corte Constitucional de Colombia. M.P Eduardo Cifuentes Muñoz; 1998; Sentencia SU-747 de 1998.

Corte IDH, Caso Almonacid Arellano Vs Chile (Excepciones preliminares, Fondo, Reparaciones y Costas), Sentencia de 26 de septiembre de 2006. Serie C No.154, pág. $52-53$

Corte IDH, Caso Castañeda Gutman vs México (Excepciones Preliminares, Fondo, reparaciones y Costas), Sentencia de 6 de agosto de 2008, Serie C No. 184.

Corte IDH, Caso López Mendoza vs Venezuela (Fondo, Reparaciones y Costas), Sentencia de 1 de septiembre de 2011, Serie C No. 233.

Corte IDH, Caso Velásquez Rodríguez Vs Honduras (Fondo Reparaciones y Costas), Sentencia de 29 de julio 1988, Serie C No. 04.

Corte IDH, Caso Yatama Vs. Nicaragua (Excepciones Preliminares, Fondo, Reparaciones y Costas), Sentencia de 23 de Junio de 2005, Serie C No. 127. 